\title{
KEPENUHAN ROH KUDUS
}

\section{OLEH: PDT. DANIEL RONDAH, TH.M.}

\section{Masalah Baptisan Roh}

Pribadi Roh Kudus adalah pribadi yang tidak kalah pentingnya dalam doktrin Kristen. Roh kudus adalah Allah sendiri. Tetapi penerapan ajaran tentang Roh Kudus menimbulkan kontroversi di dalam gereja-gereja. Topik-topik yang kontroversial itu antara lain baptisan Roh Kudus serta tanda yang mengiring baptisan roh.

Sedikitnya ada dua ajaran yang berbeda tentang baptisan Roh Kudus yang dianut gereja, khususnya bagi kaum evangelical:

1. Ajaran "Satu Paket"

Bahwa seseorang yang dibaptis air di dalam nama Kristus pada saat yang sama juga dibaptis dalam roh. Paulus menyatakan kepada jemaat di Efesus bahwa mereka dimetraikan oleh Roh Kudus pada saat mereka percaya kepada Kristus (Ef. 1:13). Sehingga tidak diperlukan lagi baptisan Roh Kudus sebagai pengalaman yang berbeda setelah baptisan dalam nama Yesus. Yang diperlukan bagi setiap orang percaya adalah berjalan di dalam Roh atau yang biasa disebut kepenuhan Roh kudus. Umumnya pandangan ini dianut oleh kaum evangelical. Bagaimana dengan adanya peristiwa baptisan Roh Kudus yang berbeda dengan pengalaman pertobatan seperti yang ada dalam Kisah Para Rasul 2, 8, 10, 19? Bagi kaum evangelical, Roh Kudus tercurah atas empat grup yaitu orang Yahudi, Samaria, orang yang takut akan Allah (God fearers) dan orang kafir, untuk menunjukkan bahwa mereka mulai saat itu terhisab di dalam gereja atau masuk dalam satu tubuh yaitu gerejanya. ${ }^{1}$ Lagipula peristiwaperistiwa yang terjadi itu bukanlah merupakan suatu pengajaran yang bersifat dogmatis atau doktrin yang harus dianut gereja dan hanya berupa kesaksian. Rumus penafsiran kaum evangelical adalah bahwa hermeneutika yang benar tentang ajaran Kristen adalah "harus dibangun hanya pada bagian-bagian Alkitab yang bersifat didaktis (bersifat ajaran).,"2

2. Pengalaman Kedua

Bahwa setiap orang yang telah dibaptis dalam nama Yesus memerlukan pengalaman kedua yaitu baptisan Roh yang berbeda waktunya dengan baptisan yang pertama. Umumnya ayatayat yang diambil adalah Kisah Para Rasul. 2, 8, 10, 19. Ayat-ayat ini dipakai untuk menjelaskan adanya pengalaman yang berbeda. Walaupun demikian mereka juga menganggap pentingnya dipenuhi oleh Roh Kudus. Umumnya pandangan ini dianut oleh gereja-gereja Pentakosta, Sidang Jemaat Allah dan Gerakan Kharismatik atau Neopentakosta (yang notabene juga masih merupakan bagian dari kaum evangelical).

Kedua ajaran ini di dalam sejarahnya tidak dapat dipersatukan dan masing-masing berpendapat bahwa ajaran mereka berasal dari Alkitab. Namun isu ini perlu diangkat untuk mengetahui bahwa gereja-gereja memiliki pemahaman yang berbeda tentang hal ini.

1. Suatu Keharusan

\section{Pentingnya dipenuhi Roh Kudus}

Kepenuhan Roh ada hubungan erat dengan pengajaran baptisan Roh itu. Setiap orang perlu mengalami kepenuhan Roh di dalam hidupnya setelah pertobatan. Efesus 5:18b berkata, \section{2), 118-9}

${ }^{1}$ Lihat penjelasan lengkap: R. C. Sproul, Essential Truths of the Cristian Fait (Wheaton, III.: Tyndale,

${ }^{2}$ Scheunemann, Sungai Air Hidup: Roh Kudus dan Pelayanan-Nya (Malang: YPPII, 1979), 169. Lihat juga prinsip yang sama yang dikembangkan oleh Gordon Fee \& Dauglas Stuart, How To Read The Bible For All It's Worth (Grand Radips, Mich: Zondervan, 1981). Fee dan Stuart berkata, "Our assumption, along with many others, is that unless Scripture explicitly tell us we must do something, what is merely narrated or described can never function in a normative way," hlm. 97. 
"Hendaklah kamu penuh dengan Roh." Ini adalah perintah yang dapat dipegang sebagai doktrin. Kata ini adalah perintah untuk setiap orang yang percaya bahwa setiap orang harus dipenuhi dengan Roh Kudus. Artinya, orang yang dipenuhi Roh Kudus adalah orang yang dipenuhi pribadi Roh Kudus itu. Dia mengusai hidup dan memiliki kehidupan seseorang. Kata ini juga berbentuk present tenseimperative dalam bahaya Yunaninya. Itu berarti bahwa kepenuhan Roh adalah hal yang diperintahkan dan yang bersifat terus menerus. D. Scheunemann berkata, "Titik berat pengajaran Perjanjian Baru tidak terletak pada suatu pengalaman Roh Kudus yang berlaku hanya pada waktu yang tepat yang tidak dapat diulangi lagi, melainkan pada pembawaan diri dalam kepenuhan Roh yang terus menerus."3 Orang percaya perlu berdoa agar Tuhan memenuhi hidupnya dengan Roh Kudus setiap hari, karena kepenuhan bisa bermakna bahwa seseorang bisa dipenuhi dan pada suatu saat ia kurang dipenuhi oleh Roh Kudus. Ilustrasi yang tepat untuk menggambarkan ini adalah bukan air di dalam gelas, tetapi seperti udara di dalam balon. Ini bukan peristiwa satu kali, tetapi terus menerus.

2. Tujuan dipenuhi Roh Kudus

Pertanyaan selanjutnya adalah apakah tujuannya dipenuhi Roh Kudus? Dalam menjawab pertanyaan ini perlu dibahas cara dan ciri dipenuhi Roh Kudus. Yang pertama menyangkut bagaimanakah seseorang dipenuhi Roh dan yang kedua adalah karakteristik orang yang dipenuhi Roh Kudus. Walaupun demikian seseorang tidaklah boleh terperangkap dengan memakai pola tertentu tentang cara seseorang dipenuhi Roh Kudus. D. Scheunemann secara tepat berkata, "Kita tidak boleh menentukan satu cara atau menggariskan satu pola tertentu tentang bagaimana kepenuhan Roh Kudus harus berlangsung dalam kehidupan Kristen. Karena justru cara-cara demikian telah mendatangkan banyak penderitaan dalam jemaat, dan mengakibatkan banyak orang Kristen mengalami pergumulan, keputusasaan, bahkan terlibat dalam peniruan yang fatal." ${ }^{4}$ Jadi sebenarnya masing-masing pribadi memiliki keunikan dalam berhubungan dengan Roh Kudus di dalam hidupnya.

Tujuannya adalah memberikan kepada orang percaya: 1) bertambahnya kuasa pelayanan; 2) bertambahnya kekudusan.

3. Prinsip dipenuhi Roh Kudus

Tidak ada cara khusus untuk dipenuhi Roh Kudus. Ada yang dengan cara yang ajaib, ada juga yang dengan cara bertahap dalam pertumbuhan iman. Walaupun cara dipenuhi tidak pernah ditetapkan di dalam Alkitab, setidaknya ada beberapa prinsip tentang bagaimana seseorang dipenuhi Roh Kudus yaitu pertama, kerinduan yang mendalam akan Tuhan. Kedua, penyerahan total, dan ketiga, ialah menerima dengan iman (Yoh. 7:37-39). ${ }^{5}$ Dapat disimpulkan bahwa ketika seseorang dipenuhi Roh tidaklah perlu baginya untuk mengalami baptisan Roh tersendiri yang berbeda dari pertobatannya. Dan tidak ada keharusan akan tanda bahasa Roh yang mengikutinya.

4. Ciri dipenuhi Roh Kudus

Sedangkan ada beberapa ciri yang menunjukkan seseorang dipenuhi oleh Roh Kudus di dalam kehidupannya. Ciri ini tidak selalu harus sempurna, namun pasti ada:

a) Kehidupan yang berisi pujian kepada Allah (Efs. 5:19-20)

b) Orang yang dipenuhi Roh Kudus akan menghasilkan buah-buah Roh (Gal. 5:22-23).

c) Orang yang dipenuhi Roh Kudus akan menyalibkan keinginan daging karena berjalan dalam pimpinan Roh (Gal. 5:24-26). Artinya, dia hidup dalam kekudusan dan berjuang

\footnotetext{
${ }^{3}$ Scheunemann, Sungai Air Hidup, 168.

${ }^{4}$ Ibid, 169.

${ }^{5}$ Ibid, 170-1.
} 
melawan semua dosa. Itu tidak berarti bahwa orang yang dipenuhi Roh adalah orang yang sempurnah, tetapi senantiasa berjuang melawan segala keinginan daging.

d) Kepenuhan rih adalah penting dalam pelayanan seseorang, dimana kepenuhan Roh memampukan seseorang dalam melakukan pelayanan (Kis. 4:31; 5:3).

1. Bahasa Roh sebagai Karunia

\section{Tentang Bahasa Roh}

Bahasan terakhir yang tak dapat diabaikan adalah tentang bahasa Roh. Kelompok gereja tertentu menganggap bahwa bahasa roh adalah tanda dari orang yang sudah dibaptis oleh Roh Kudus dan bukti dari kepenuhan Roh Kudus. Tentang hal inipun terjadi perbedaan pendapat. Bila melihat pengajaran Perjanjian Baru, maka dapat disimpulkan bahwa bahasa Roh adalah salah satu karunia di dalam gereja.

Di dalam Perjanjian Baru ada tiga bagian dari 27 buku Perjanjian Baru. Referensi tentang bahasa Roh terdapat dalam tiga bagian yaitu di dalam kisah (Kisah Para Rasul. 2:1-13; 10:111; 18:24; 19:7), kemudian terdapat satu bagian di dalam I Korintus 12-14 dan satu frase singkat dalam Injil Markus 16:17. Dapat disimpulkan bahwa bila benar bahasa Roh adalah sesuatu yang penting bagi umat Kristen, tentulah Paulus harus menyebutnya dalam kitabkitabnya yang lain, tetapi yang ada adalah sebaliknya.

Di dalam daftar karunia-karunia yang didaftarkan oleh Paulus, ternyata karunia bahasa Roh ditempatkan terakhir dalam dua daftar (I Kor. 12:8-10, 28) dan tidak disebutkan dalam Efesus 4:11 dan Roma 12:6-8. Ini menunjukan bahwa karunia ini bukanlah yang terpenting dalam kehidupan bergereja.

Paulus yang sering mengatakan bahwa karunia bahasa Roh tidaklah sepenting yang lain. Misalnya, hal ini terdapat dalam I Korintus $12: 28-31$; 14:5,19. Paulus juga menjelaskan bahwa karunia bahasa Roh tidaklah untuk setiap orang (I Kor. 12:29-30). Ini menunjukkan bahwa bahasa Roh bukanlah tanda utama dari kepenuhan Roh dan tidak diharuskan dalam pertumbuhan iman orang percaya. Paulus juga tidak mensyaratkan bahasa Roh dalam pemilihan penatua dan diakon (II Tim. 3:1-13; Titus 1:5-9). Pemimpin gereja tidak diberikan syarat untuk memiliki karunia bahasa Roh.

2. Karunia Bahasa Roh Masih Ada

Walaupun bahasa Roh tidak sepenting yang kita bayangkan dalam kehidupan bergereja, namun eksistensinya sampai hari ini masih ada. Salah satu argumen yang saya pakai adalah bahwa bila karunia yang lain masih ada, maka secara logika karunia ini pun masih ada. Yang lainnya adalah bahwa dalam perjalanan sejarah gereja sampai tumbuh pesatnya gerakan Pantekosta dan Neo-Pantekosta di abad ke-20 ini, maka mau tidak mau hal yang perlu diakui tentang masih eksisnya bahasa Roh.

3. Bagaimana dengan Praktek Bahasa Roh Dewasa ini?

Bahasa Roh sebagai fenomena gereja modern perlu dimengerti sebagai karunia dari Allah. Tetapi, sebagaimana J. I. Packer mengamati bahwa saat ini bahasa Roh adalah "Sought and used as part of a quest for closer communion with God and regularly proves beneficial at conscious level, bringing relief of tension, a certain inner exhilaration, and a strengthening sense of God's presence and blessing." Ia juga menambahkan, "Glossolalia represents, focuses, and intesifies such awareness of divine reality as is brought to it; thus it becomes a natural means of voicing the mood of adoration, and it is not surprising that charismatics 
should call it their "prayer language." Kemudian dia menyimpulkan, "All this argues that for some people, at any rate, glossolalia is a good gift of God, just as for all of us power to express thought in language is a good gift of God." ${ }^{6}$ Maksudnya, bahasa Roh saat ini merupakan suatu upaya untuk mendekatkan diri kepada Tuhan dan memakai bahasa sebagai bahasa doa. Dan itu dapat dikatakan sebagai pemberian Allah, yang sama dalam tiap orang ketika dia mengekspresikan doanya kepada Tuhan di dalam bahasanya masing-masing.

Akhirnya, memakai bahasa Roh perlu berhati-hati agar tidak memanipulasi secara psikologis orang lain. Firman Tuhan mengingatkan, "sesungguhnya, Aku akan menjadi lawan para nabi, demikianlah Firman Tuhan, yang memakai lidahnya sewenang-wenang untuk mengutarakan firman Ilahi. Sesungguhnya, Aku akan menjadi lawan mereka yang membuatkan mimpi-mimpi dusta, demikianlah firman Tuhan, dan yang menceritakannya serta menyesatkan umat-Ku dengan dustanya dan dengan bualnya. Aku tidak pernah mengutus mereka dan tidak pernah memerintahkan mereka. Mereka sama sekali tiada berguna untuk bangsa ini, demikianlah firman Tuhan” (Yer. 23:31-32). Hal ini menjadi awasan bagi setiap orang yang menyatakan diri menerima karunia bahasa Roh, nubuat, penglihatan, dan karunia ajaib lainnya.

\section{(Footnotes)}

1 Lihat penjelasan lengkap: R. C. Sproul, Essential Truths of the Cristian Fait (Wheaton, III.: Tyndale, 1992), $118-9$.

${ }^{2}$ Scheunemann, Sungai Air Hidup: Roh Kudus dan Pelayanan-Nya (Malang: YPPII, 1979), 169. Lihat juga prinsip yang sama yang dikembangkan oleh Gordon Fee \& Dauglas Stuart, How To Read The Bible For All It's Worth (Grand Radips, Mich: Zondervan, 1981). Fee dan Stuart berkata, "Our assumption, along with many others, is that unless Scripture explicitly tell us we must do something, what is merely narrated or described can never function in a normative way," hlm. 97.

${ }^{3}$ Scheunemann, Sungai Air Hidup, 168.

${ }^{4}$ Ibid, 169.

${ }^{5}$ Ibid, 170-1.

${ }^{6}$ J. I. Packer, Keep in step with the Spirit (Old Tappan, NJ: Flemming H. Revell Co., 1984), 210-11.

\footnotetext{
${ }^{6}$ J. I. Packer, Keep in step with the Spirit (Old Tappan, NJ: Flemming H. Revell Co., 1984), 210-11.
} 